\section{INTEGRALIDADE NA SAÚDE E FORMAÇÃO PROFISSIONAL: VIVÊNCIA DE ESTUDANTES DE FISIOTERAPIA}

\author{
INTEGRALITY IN HEALTH AND PROFESSIONAL TRAINING: \\ PHYSICAL THERAPY STUDENTS' EXPERIENCE
}

Maria Julia de Siqueira e Torres Nunes (Orcid: 0000-0002-7271-3750.)

Juliana Monteiro Costa (Orcid: 0000-0002-6976-8670.) ${ }^{2}$

Thálita Cavalcanti Menezes da Silva (Orcid: 0000-0002-5093-3680.) ${ }^{2}$

Autor correspondente:

Maria Julia de Siqueira e Torres

Nunes

e-mail: mariajulianunes@yahoo. com.br

${ }^{1}$ Departamento de Fisioterapia, Centro Universitário Tabosa de Almeida - ASCES/UNITA

2 Departamento de Psicologia, Faculdade Pernambucana de Saúde

\section{RESUMO}

Objetivo: investigar a vivência da integralidade em saúde de estudantes do curso de fisioterapia. Métodos: estudo qualitativo, realizado em uma Instituição de Ensino Superior de Pernambuco, por meio de um grupo focal com estudantes do curso de fisioterapia. A discussão foi gravada, transcrita e analisada pela Técnica de Análise de Conteúdo Temática, a partir das três etapas propostas por Minayo. Resultados e discussão: as sete participantes da pesquisa eram do sexo feminino, com média de idade 23,4 anos. Observou-se um conhecimento aprofundado sobre a integralidade na saúde. Entre os fatores potencializadores, foram abordados o modelo de estágio integrado, a presença dos preceptores como auxiliares na formação do perfil profissional e a inserção precoce na prática com abordagem biopsicossocial dos sujeitos, com ênfase na atenção básica. Como principal fragilidade, foi citado o perfil do profissional com formação no modelo biomédico e consequente dificuldade em trabalhar no modelo de integralidade. Conclusão: as estudantes mostraram conhecimento acerca da integralidade na saúde, não apenas no seu conceito básico, mas incorporando o seu amplo sentido no cuidado aos pacientes. Elas percebem a complexidade dos sujeitos na sua totalidade, e não de forma compartimentalizada. Apesar dos resultados satisfatórios quanto à vivência e à incorporação da integralidade na formação das estudantes, por se tratar de uma pesquisa de natureza qualitativa com um pequeno número de participantes e de apenas com um curso, não se pode generalizar os dados. Portanto, sugerem-se pesquisas com outras Instituições públicas e privadas de Pernambuco que ofertam o curso de fisioterapia.

Palavras-chave: Integralidade em saúde; Fisioterapia; Educação superior.

\begin{abstract}
Objective: to investigate the health integrality experience of physiotherapy students. Methods: a qualitative study, carried out in a Higher Education Institution of Pernambuco, through a focus group with students of the physiotherapy course. The debate was recorded, transcribed and analyzed by the Thematic Content Analysis Technique, based on the three steps proposed by Minayo. The research followed the norms and guidelines proposed by Resolution $510 / 2016$ of the CNS and the project was approved by the Research Ethics Committee of the Faculdade Pernambucana de Saúde, under the opinion number 2,624,085 and CAAE 87127718.4.0000.5569. All participants signed the Informed Consent Term. Results and discussion: the seven participants in the study were female, with a mean age of 23.4 years. In-depth knowledge about integrality in health was observed. Among the potentiating factors were the integrated stage model, the presence of preceptors as auxiliaries in the formation of the professional profile and the early insertion in the practice with biopsychosocial approach of the subjects, with emphasis on basic care. The profile of the professional with training in the biomedical model and consequent difficulty in working on the integrality model was mentioned as the main weakness. Conclusion: the students showed knowledge about integrality in health, not only in its basic concept, but incorporating its broad meaning in the care of patients. They perceive the complexity of the subjects in their totality and not in a compartmentalized way. Despite the satisfactory results regarding the experience and incorporation of integrality in the training of the students, because it is a qualitative research with a small number of participants and only with one course, one can not generalize the data. Therefore, we suggest researches with other public and private institutions of Pernambuco that offer the physical therapy course.
\end{abstract}




\section{INTRODUÇÃO}

A prática da integralidade na saúde, principal diretriz do Sistema Único de Saúde (SUS), tem sido ponto de discussão frequente por estudiosos da área da educação em saúde. Atrelada ao entendimento dessa prática, observa-se a necessidade de compreender as potencialidades e as fragilidades da formação acadêmica que interferem na fomentação desse princípio, ressaltando a importância das Instituições de Ensino Superior (IES) em fornecer uma formação adequada, e do Estado, em supervisionar e incentivar, por meio de políticas educacionais, as relações Ensino-Serviço-Assistência ${ }^{1-4}$.

Nesse sentido, o SUS apresenta três princípios doutrinários que norteiam as suas ações: universalidade, equidade e integralidade. A integralidade é definida como "[...] um conjunto articulado e contínuo das ações e serviços preventivos e curativos, individuais e coletivos, exigidos para cada caso em todos os níveis de complexidade do sistema"s. Ou seja, a assistência de forma integral requer ações direcionadas tanto para a reabilitação do sujeito doente quanto para a prevenção. Nessa perspectiva, essas ações de forma integral conduzem a um atendimento humanístico, o que implica também a autonomia e o protagonismo dos sujeitos no seu processo de cuidado. A corresponsabilização entre o usuário, os seus familiares, os trabalhadores da saúde e os gestores, juntamente com a multidisciplinaridade da equipe de saúde e a transversalidade do sistema, fortalece a assistência ${ }^{6}$.

Em contrapartida, a ineficaz regulação pelo SUS da demanda entre profissionais de saúde-usuário, a baixa remuneração desses trabalhadores e a exigência mercadológica divergente da real necessidade da população são fatores que confluem para a fragilidade das ações humanizadas. Além desses elementos, a sensibilização e o preparo dos profissionais envolvidos no cuidado somam-se às fragilidades ${ }^{7-9}$.

Um dos aspectos que podem fortalecer a integralidade é uma transformação no processo de formação dos profissionais da área de saúde. Para tal, é imprescindível que a formação em saúde esteja baseada no modelo vigente do país, voltado para a atenção integral, em um sistema de referência e contrarreferência, com trabalho em equipe ${ }^{10}$.

As Diretrizes Curriculares Nacionais (DCN) do Curso de Graduação em Fisioterapia versam que o egresso fisioterapeuta deve ter formação generalista, humanista, crítica e reflexiva, estando capacitado a atuar em todos os níveis de atenção à saúde, com base no rigor científico e intelectual ${ }^{11}$. Apesar disso, as IES, em sua maioria, embora reconheçam a necessidade de transformação no modelo de ensino, apresentam dificuldades em estabelecer estratégias pedagógicas visando a essa formação. Sendo assim, tendem a formar fisioterapeutas tecnicistas, com foco na reabilitação e na cura. $\mathrm{O}$ cerne geralmente é na doença, divergindo dos modelos de atenção à saúde que se adequam melhor à realidade epidemiológica e sanitária do país ${ }^{12}$.

Trabalhos realizados com estudantes do curso de fisioterapia apontam para a utilização de metodologias ativas na sua formação, possibilitando a aproximação do estudante com o sistema de saúde vigente. Vários estudos indicam que a utilização de métodos em que o estudante se torna o protagonista do seu processo de aprendizagem, tais como a Aprendizagem Baseada em Problemas (ABP) e a Problematização, são eficazes para aquisição de raciocínio clínico e solução de $\operatorname{casos}^{13-17}$.

Dolmans e colaboradores ${ }^{18}$ ratificam que a ABP tem um potencial de preparar o estudante de forma mais eficaz por utilizar alguns princípios essenciais na aprendizagem. Os autores norteiam que a o processo de aprendizagem deve seguir quatro ideais: o da aprendizagem 
de forma construtiva, enfatizando que ela é um processo ativo, cujos estudantes constroem e reconstroem suas conexões de conhecimento; o autodirecionamento, em que os estudantes são ativos no planejamento, monitorização e avaliação do seu processo de aprendizagem; o processo colaborativo, descrito como a interação mútua entre duas ou mais pessoas a fim de compartilhar entendimentos sobre um dado problema; e de forma contextual, levando em consideração que a situação em que um conhecimento é adquirido determina se ele será usado ou não. Contextos profissionais relevantes com problemas com múltiplas perspectivas estimulam o conhecimento de forma significativa.

Com o objetivo de analisar a percepção dos estudantes de fisioterapia acerca da integralidade e a incorporação desse princípio doutrinário na formação acadêmica, Almeida e colaboradores ${ }^{19}$ realizaram um estudo de natureza qualitativa em três IES do Distrito Federal (DF). Os pesquisadores conduziram três grupos focais, cada um composto por dez graduandos do último ano do curso de fisioterapia; e, após análise do conteúdo, constataram que, apesar das DCN do curso de fisioterapia pontuarem a necessidade da formação humanística e integral, os estudantes de fisioterapia chegam ao último ano da graduação com uma ideia vaga e repartida do conceito de integralidade na saúde.

Nessa perspectiva, entendendo que a assistência em saúde voltada para o modelo SUS requer o cuidado do ser humano em toda sua complexidade de forma biopsicossocial e que a atual formação em saúde se apresenta ainda pautada no modelo hegemônico biomédico, que vai de encontro ao modelo da integralidade, desenvolveu-se o presente estudo. Assim, buscou-se compreender a vivência dos graduandos do curso de fisioterapia de uma IES privada de Pernambuco acerca da integralidade na saúde e como se dá inclusão desse princípio doutrinário na sua formação.

\section{MÉTODO}

Trata-se de um estudo qualitativo realizado em uma IES do Agreste de Pernambuco. O curso de fisioterapia foi iniciado em 2004; e, desde o primeiro semestre de 2015, a IES implantou uma proposta de integralidade para o estágio obrigatório do curso, em que os estudantes do nono e décimo períodos têm a oportunidade de vivenciar a junção de todos os conhecimentos dos anos anteriores na prática. Atualmente, a faculdade utiliza metodologias ativas, como a problematização, além da metodologia tradicional no seu curso de fisioterapia.

O período do estudo foi de junho de 2018 a maio de 2019. A coleta de dados aconteceu apenas após avaliação e aprovação do projeto pelo Comitê de Ética em Pesquisa (CEP) da Faculdade Pernambucana de Saúde (FPS) sob o parecer número 2.624.085 e CAAE 87127718.4.0000.5569.

Todos os estudantes do último período de graduação em fisioterapia da referida IES que estivessem regularmente matriculados e finalizando a disciplina Estágio Supervisionado II no momento da coleta de dados, em junho de 2018, foram convidados a participar da pesquisa. Foram excluídos os estudantes que estivessem afastados por licença médica ou por qualquer outro motivo que promovesse impedimento da sua participação.

Após o convite e a aceitação dos participantes da pesquisa, foram agendados o local, o dia e a hora para a realização da coleta dos dados. Para tal, foi escolhido o Grupo Focal (GF). Essa técnica, a partir da interação grupal, permite uma ampla problematização sobre um tema ou foco específico. Foi realizado o GF com um grupo de sete estudantes do curso de fisioterapia. $\mathrm{O}$ debate foi norteado por roteiro previamente estabelecido.

O GF é caracterizado por discussões que ocorrem sobre um tema específico quando os participantes recebem estímulo apropriado, que é dado por perguntas que norteiam o debate. Essa técnica distingue-se por suas características próprias, especialmente pela interação grupal, que é uma resultante da busca de dados. Além de permitir ao pesquisador um maior aprofundamento do tema, proporciona o entendimento de como os fatos são articulados, 
censurados, confrontados e alterados por meio da interação grupal. Preconiza-se pela literatura o mínimo de 6 e o máximo de 12 participantes; e o GF foi realizado conforme o critério de saturação de conteúdo, ou seja, quando a coleta de novos dados não traz mais esclarecimentos para o objetivo do estudo ${ }^{20}$.

Os debates em grupo foram gravados, conforme autorização prévia de todos os participantes de pesquisa emitida pelo Termo de Consentimento Livre e Esclarecido (TCLE), e, posteriormente, transcritos na íntegra para análise dos dados. Após o término do GF, os debates foram transcritos para documentos do Word $\AA$, e os áudios foram apagados. Os participantes da pesquisa foram identificados por números, tais como estudante 1 , estudante 2 , preservando o anonimato e salvaguardando-os de possíveis desconfortos durante a coleta de dados.

O conteúdo dos debates do GF foi analisado por meio da Técnica de Análise de Conteúdo Temática. A análise de conteúdo conceitua-se como um conjunto de técnicas de comunicação, que se utiliza de procedimentos sistemáticos e objetivos de descrição do conteúdo das mensagens, sendo falas e expressões corporais, que permitam o entendimento do conhecimento do grupo sobre $\mathrm{o}$ assunto pesquisado $\mathrm{o}^{20,21}$.

\section{RESULTADOS E DISCUSSÃO}

A coleta de dados foi realizada com sete estudantes que compareceram ao GF. Todas as participantes da pesquisa foram do sexo feminino, com média de idade de 23,4 anos, com idade mínima de 22 anos e máxima de 26 anos. Apenas uma estudante era casada, e as outras seis eram solteiras; nenhuma tinha filhos, e todas residiam na mesma cidade que estudavam no período da coleta de dados. Três delas eram domiciliadas em diferentes cidades do interior de Pernambuco antes de iniciar o curso de fisioterapia. Nenhuma das participantes da pesquisa exercia atividade laboral durante a graduação. Quanto à religião, quatro definiram-se católicas, duas evangélicas e uma afirmou não ter religião.

A partir da transcrição e da análise da discussão, estabeleceu-se o tema Integralidade na Saúde e Formação Profissional, em que foram estabelecidas categorias de relevância para discussão. As estudantes que participaram da pesquisa foram identificadas por um número predefinido, salvaguardando-as de possíveis desconfortos e preservando a fidedignidade do debate.

Por intermédio da correlação dos objetivos propostos com a transcrição do debate, emergiram quatro categorias de análises que cumprem o propósito desta pesquisa, a saber:

1. Integralidade na saúde: vivência de estudantes de fisioterapia;

2. Potencialidades e fragilidades na prática da integralidade na saúde na perspectiva dos estudantes de fisioterapia;

3. Formação e atuação em saúde na perspectiva da integralidade;

4. O estágio integrado como parte essencial para a integralidade

Sendo assim, nesta etapa, serão discutidas as falas das estudantes correlacionando-as com a literatura existente sobre o tema.

Integralidade na saúde: vivência de estudantes de fisioterapia

A respeito do conhecimento das estudantes acerca da integralidade, observa-se, de maneira geral, que elas a definem de forma ampla, apoderando-se não apenas do conceito teórico, mas também exemplificando a maneira como a integralidade foi vivenciada na sua prática acadêmica. Elas percebem a complexidade dos sujeitos, olhando-os de maneira integrada, e não compartimentalizada, conforme explicitado nas falas a seguir: 
Quando a gente fala em integralidade, a gente vê logo na mente a forma de abordagem, a forma como você vai acolher esse paciente. A gente enxerga no paciente não só a questão da doença, mas todo um contexto em que ele está inserido. O contexto familiar, o contexto social, e de que forma isso vai interferir na qualidade de vida do paciente. Então é uma forma muito mais abrangente de acolher. (Estudante 1)

A gente observa todos os aspectos dele (paciente); o ambiente em que ele está inserido, o aspecto psicossocial e também a patologia que ele apresenta. (Estudante 3)

Apesar do seu conceito polissêmico, de acordo com a Lei Orgânica da Saúde de 1990, a integralidade é definida como "um conjunto articulado e contínuo de ações e serviços preventivos e curativos, individuais e coletivos, exigidos para cada caso, em todos os níveis de complexidade do sistema"s.

Um conceito frequentemente utilizado no meio acadêmico acerca da integralidade reconhece o paciente, entendendo, de forma errônea, que um profissional será capaz de solucionar todas as demandas do sujeito1. As estudantes, apesar de falarem essa definição popularizada, perpassam-na, entendendo que a totalidade diz respeito à multiplicidade de fatores desencadeadores do processo saúde-doença do sujeito, em que o adoecimento é a soma do biológico, ambiental, social, cultural e econômico.

Além disso, as estudantes conseguem enxergar a integralidade além da sua área específica de atuação, seja da grande área da fisioterapia ou das áreas distintas. As falas descritas abaixo deixam clara a necessidade do trabalho multidisciplinar para um tratamento adequado.

É importantíssima a questão do atendimento integral porque a gente tá saindo agora, então a gente tem que ter uma noção de como a gente vai se comportar lá fora diante de um paciente com várias necessidades em relação à patologia e ao que mais a gente puder ajudar.

\section{(Estudante 4)}

É importante a gente mostrar ao paciente que a gente é capaz de atender várias necessidades dele naquele atendimento. (Estudante 6)

A discussão acerca da integralidade recai sobre a humanização do atendimento. Essa reflexão humanística abrange as circunstâncias sociais, éticas, educacionais e psíquicas presentes nas relações humanas, devendo ser valorizadas nos atendimentos de saúde ${ }^{11,22}$.

Acredito que é muito interessante essa temática, principalmente nos dias atuais, que está cada vez mais tentando trazer esse atendimento humanizado... Ele [o paciente] se sente seguro, tem confiança no profissional. Então eu acredito que é algo que tenha que ser bastante discutido não apenas na fisioterapia, mas na saúde como um todo. (Estudante 1)

Eu fico observando no estágio as pessoas que passam pelas disciplinas, principalmente em pediatria. Como as alunas chegam na mãe, falam, brincam com o bebê. Tudo isso a gente aprendeu aqui na graduação, sabe? Como o professor trata o paciente, a partir do momento que o paciente entra na clínica escola, até o momento que ele sai. A forma como ele trata influencia a gente a tratar da mesma forma. Então isso torna a gente uma pessoa mais humana. (Estudante 2)

Os discursos supracitados estão de acordo com Oliveira e Cutolo8, quando explicam as relações existentes entre integralidade e humanização na saúde. Em uma ação profissional integral, soma-se ao biológico o acolhimento, a escuta, o vínculo e o estabelecimento das relações de confiança paciente-profissional de saúde. Nesse entendimento, humanização e integralidade são práticas estreitas entre si e coexistentes, já que as abordagens de forma integral geram ações humanizadas.

Não obstante, o presente estudo difere dos achados da pesquisa realizada por Almeida e pesquisadores 19, na qual os autores ressaltam que os estudantes 
de fisioterapia de três IES de Brasília-DF tinham uma visão vaga e repartida do conceito de integralidade. Tal divergência pode ser explicada em virtude de modelos pedagógicos e currículos divergentes.

Potencialidades e fragilidades na prática da integralidade na saúde na perspectiva dos estudantes de fisioterapia

No relato das estudantes, observam-se vários fatores que fortalecem a integralidade. Dentre eles, destacam-se a presença dos preceptores, que auxiliam os estagiários na construção do raciocínio clínico, e os variados campos de estágio por onde os estudantes passam, sobretudo os ambientes de atenção primária. Esse é um setor que permite mais facilmente o atendimento multidisciplinar pela gama de profissionais existentes, além da atenção básica ser a área em que mais se vivencia a integralidade na saúde.

Ademais, a importância desses estágios decorre do fato de o estudante conseguir enxergar a realidade do paciente de perto, realizando visitas domiciliares, ficando a par da sua rotina de atividades de vida diária, bem como sendo capaz de identificar os fatores biopsicossociais que influenciam no seu processo saúde-doença.

Os relatos das estudantes corroboram a literatura ao citarem outros fatores referentes ao currículo que as estimulam a apreender a vivência da integralidade na saúde, tais como a inserção precoce na prática, sobretudo voltada à atenção básica, sem desvalorizar a atenção especializada; a utilização de metodologias ativas construtivistas e problematizadoras no processo de ensino aprendizagem e o foco voltado para a necessidade do usuário do SUS ${ }^{19,23-25}$.

Foi muito rica a graduação, principalmente os estágios do $9^{\circ}$ e $10^{\circ}$ (periodos) porque é um mundo totalmente diferente do que a gente começa no $5^{\circ}$. A gente aprende coisa nova, aprende muito, todo dia e rápido. E isso é extremamente importante e rico pra nossa saída da faculdade. [...] o estágio é auxiliado por muitos profissionais (preceptores). Eles nos ajudam a perceber mais como tratar o paciente e seguir na abordagem em relação às patologias que ele apresenta. (Estudante 4)
O campo de estágio externo [fora da clínica escola] abre mais a nossa mente pra isso [integralidade], porque no interno não é tanto assim, mas quando a gente sai um pouquinho da nossa zona de conforto, a gente consegue enxergar uma realidade maior. (Estudante 2)

Sobre a formação profissional, as estudantes concordam que sua formação é voltada para o SUS, com atendimento integral e humanizado; entretanto, encontram dificuldades na relação com outros profissionais formados há mais tempo e que parecem não vivenciar esse atendimento integral. Elas concordam que as fragilidades estão especialmente nesses profissionais que têm dificuldades no atendimento de forma integral. Além disso, as estudantes assinalaram ainda a alta demanda de usuários para poucos profissionais.

Eu acredito que um dos fatores que dificultam é a demanda. Muitas vezes o local tem uma demanda grande de pacientes e eles terminam negligenciando essa integralidade. (Estudante 3)

Eu acredito que uma das dificuldades que seria uma barreira é com relação à formação. [...] desde o princípio a gente vem sendo instruído pra ter esse olhar mais integral [...] essa atuação multiprofissional. A gente sentiu essa dificuldade nos campos externos, desses profissionais que não tinham esse olhar. Acho que é uma questão de educação permanente, que esses profissionais precisariam de uma formação melhor, tendo essa visão mais integralizada. (Estudante 1)

Os relatos supracitados fazem referência à necessidade de constante aperfeiçoamento de pessoal, que, na Lei Orgânica da Saúde de 1990, já estava prevista no tópico relativo aos recursos humanos $^{25}$. A necessidade de atualizações baseadas na política de Educação Permanente em Saúde (EPS) objetiva qualificar e aperfeiçoar o processo de trabalho nos diferentes níveis do sistema de saúde, com consequente melhoria do acesso do usuário, qualidade e humanização dos serviços, 
além do fortalecimento da tríade gestão-profissionais de saúde-usuários ${ }^{26}$.

No estágio nos postos de saúde a gente teve essa vivência com vários profissionais; tanto fisioterapeutas, como médicos, enfermeiros, agentes de saúde. [...] Toda a equipe dá o suporte àquele paciente pra que ele evolua de forma mais rápida e dê qualidade pra ele. (Estudante 2)

A partir desses estágios é que a gente vai entender melhor como funciona, tanto em relação aos postos de saúde, como nos hospitais, que também é atendimento SUS. (Estudante 4)

De acordo com Bispo Júnior ${ }^{7}$, a formação em fisioterapia deve ser estruturada primordialmente nos princípios do SUS. O olhar deve voltar-se para os níveis primário e secundário de atenção, e não apenas para o terciário; ainda assim, o foco da fisioterapia continuará sendo a movimentação humana. Com essa inclusão, a fisioterapia deixa de ser conhecida apenas como a profissão da reabilitação.

Outrossim, o papel do preceptor de estágio tem sua importância marcadamente reconhecida pelos estudantes, sobretudo na formação da sua identidade profissional. Lorenz ${ }^{27}$ define o preceptor como um mediador e agregador dos profissionais da equipe, à medida que lida com as diferentes situações que percorrem o estágio, solucionando conflitos, sanando dúvidas, questionamentos dos estudantes, da equipe, da família e dos próprios pacientes. Esse profissional deve ser capaz de permitir-se uma reconstrução constante e favorecer a construção do estudante em um perfil de trabalhador para o SUS.

Eu estou satisfeita com a formação que eu tive. Os profissionais que têm aqui na instituição ensinaram pra gente tanto conteúdo teórico e prático, como mostram pra gente todos os dias como ser uma pessoa melhor, como ser um profissional melhor pra população em geral. (Estudante 3)

Entre os fatores que influenciam a formação acadêmica, a organização dos serviços de saúde, os valores sociais e culturais, o modelo econômico vigente e as prioridades políticas são os que principalmente refletem no perfil do egresso fisioterapeuta. Vê-se um grande número de profissionais que buscam a "hiperespecialização" e limitam a sua atuação profissional e visão de integralidade do paciente. Em concordância com Silva e Da Ros ${ }^{13}$, essa "hiperespecialização" é percebida pelos estudantes e é vista em algumas situações como fragilidade na assistência integral e humanizada.

...o que a gente observa é muito especialista. Especialista na área de traumato, especialista na área de reumato, enfim... e que o paciente procura esse profissional, mas ele também tem outras necessidades. Ele geralmente não vai chegar com uma queixa só. Talvez aquele problema esteja repercutindo em outros sistemas, então é uma forma também do profissional fazer esse atendimento 'integralizado', tentando atingir todas as necessidades do paciente. (Estudante 1)

Em relação às fragilidades da prática integral, observam-se problemas em várias áreas da saúde, desde a formação desses profissionais até os entraves estruturais dos serviços. No que concerne à formação profissional, apesar de o SUS ser o sistema de saúde brasileiro vigente há mais de 30 anos, a relação ensino-saúde, historicamente, tem sido contraproducente à relação serviço-saúde. Nesse sentido, as IES têm um papel primordial em considerar o amplo e heterogêneo cenário de atendimento e em ofertar aos estudantes essa variabilidade de experiências com foco na assistência às necessidades do usuário do SUS $^{26}$.

Por parte de alguns profissionais de saúde, vê-se o seu desestímulo, pela falta de estrutura básica dos serviços, além do despreparo para lidar com determinadas situações devido à sua formação voltada para o modelo hegemônico biomédico, sendo esse último fator o mais relatado nas pesquisas ${ }^{1,2,26}$.

Formação e atuação em saúde na 
perspectiva da integralidade

A formação voltada para o modelo centrado na doença torna-se uma barreira à assistência integral. Quando questionados sobre os diferentes cenários de prática, as estudantes foram enfáticas sobre a vivência da integralidade: enquanto nos estágios voltados à atenção primária e secundária elas vivenciaram a integralidade de forma mais explícita e corriqueira, na área assistencial, elas encontraram limitações.

Percebe-se que a multidisciplinaridade e a interdisciplinaridade também estão presentes nos ambientes assistenciais especializados, como na Unidade de Terapia Intensiva (UTI). Entretanto, a pluridisciplinaridade e a transdisciplinaridade, outras modalidades da integralidade, não são bem estabelecidas nesse cenário.

Outro ponto discutido pelas estudantes foi o preparo para o estágio curricular obrigatório com utilização de metodologias ativas e um currículo composto por disciplinas que proporcionam esse entendimento de saúde integral.

Sempre era muito discutida a questão da funcionalidade relacionada a CIF. A gente usava o manual da CIF para avaliar o paciente de forma funcional, tendo esse olhar mais integralizado. [...] A gente teve o Encontro de Integração Ensino-Serviço...o aluno teve a oportunidade de fazer o seu relato de experiencia falando sobre essa questão do atendimento integralizado. (Estudante 1)

A Classificação Internacional de Funcionalidade, Incapacidade e Saúde (CIF) é um instrumento aprovado pela Organização Mundial da Saúde (OMS), em 2001, com finalidade de classificar qualitativamente a funcionalidade e a incapacidade de forma individual ou coletiva dos sujeitos. Tal sistema é reflexão da nova abordagem biopsicossocial do processo saúde-doença, que leva em consideração as perspectivas biológica, social, ambiental e econômica, em uma relação multidirecional ${ }^{28}$. O uso da CIF permite ao estudante uma visão ampla dos determinantes do processo de adoecimento e uma abordagem aos pacientes de forma integral e direcionada para sua especificidade.

Aguilar-da-Silva e Rocha Júnior ${ }^{24}$ esclarecem que a estruturação pedagógica não significa fazer do estágio um momento de teoria em detrimento da prática, mas, sim, que as reflexões advindas do momento prático possam facilitar a estruturação e aplicação dos conceitos cognitivos aprendidos em momento anterior. Em sua pesquisa, esses autores concluíram que a utilização da problematização no estágio ultrapassou o exercício intelectual, já que as tomadas de decisões estavam alicerçadas na realidade vivenciada pelos estudantes.

Em um ambiente de UTI o paciente tem outros tipos de alterações que não estão ao nosso alcance de resolver. Então existe a conversa entre a equipe: qual o outro tipo de profissional que esse paciente precisa? (Estudante 2)

Matos e pesquisadores ${ }^{29}$ avaliaram a contribuição do estágio extracurricular no processo de aprendizagem de estudantes de fisioterapia em duas IES da Bahia. Foram entrevistados estudantes que estagiaram na atenção especializada hospitalar, em ambiente de UTI, e estudantes que estagiaram em clínica de fisioterapia. Os autores concluíram que os estudantes que estagiaram na alta complexidade conseguiram desenvolver mais competências e habilidades quando comparados aos estagiários de ambulatório de clínica. A alta demanda dos pacientes nesse último ambiente, limitando a possibilidade de discussão entre preceptor e estudante, foi fator decisivo para os resultados.

Signorelli e outros pesquisado$\operatorname{res}^{23}$ analisaram os resultados da implementação em andamento de um projeto político-pedagógico no curso de fisioterapia de uma universidade no Pará com organização curricular baseada em três eixos: Fundamentos Teórico-Práticos (FTP), que têm ênfase na aproximação do estudante com a realidade profissional, especificamente voltados para o SUS; Projetos de Aprendizagem (PA), que englobam a 
tríade ensino-pesquisa-extensão; e Inclusões Culturais e Humanísticas (ICH), momento diferenciado para os estudantes em integração com outros cursos e com a comunidade, voltados para a compreensão da complexidade do ser humano de forma integral. Tal projeto pauta-se nas metodologias ativas de ensino; e, segundo os autores, os estudantes demonstram visão crítico-reflexiva diferenciada, conforme preconizada pelas DCN.

Em outro estudo realizado em Brasília-DF, Almeida e colaboradores ${ }^{19}$ analisaram as percepções e as opiniões de estudantes de fisioterapia do último ano da graduação acerca da integralidade na assistência. Os autores identificaram que há pouco preparo, ou até mesmo despreparo em relação à capacitação docente e incentivo das IES ao conduzir e implantar estratégias pedagógicas que rompam com o tradicional modelo fragmentado de formação para estabelecer o modelo da integralidade, dificultando, assim, o entendimento mais profundo acerca da temática da integralidade.

No nosso estudo, pudemos verificar que o currículo da IES estabelece o início de atividades que unam teoria e prática desde o ciclo básico e que as atividades elaboradas pelos docentes correspondem a essa perspectiva.

O estágio integrado como parte essencial para a integralidade

Os currículos dos cursos de fisioterapia são organizados de modo que os estágios obrigatórios sejam cumpridos nos diferentes cenários, abrangendo os três níveis de atenção. O que acontece é que as IES, por meio das DCN, têm autonomia na distribuição da carga horária obrigatória dos estágios nos diferentes níveis de atenção $^{11}$.

$\mathrm{Na}$ IES onde foi realizada a presente pesquisa, o currículo é organizado de modo que os estágios obrigatórios que acontecem no último ano da graduação são integrados de forma que as subáreas da fisioterapia estejam interligadas, interdisciplinarmente. Na perspectiva das estudantes, essa organização curricular é um diferencial na formação delas e potencializadora do atendimento integral. Elas entendem que o estágio organizado desse modo propicia a saída da especificidade para a integralidade, conferindo-lhes mais liberdade e autonomia no atendimento ao paciente.

A gente enxerga as coisas muito especificas e quando a gente chega no estágio a nossa mente tem que abrir novos horizontes para tratar o paciente como um todo. Quando a gente sair, cada um vai escolher sua área, né? Mas a gente consegue entender um pouco de cada uma. (Estudante 2)

O que realmente prepara a gente é essa gama de lugares que a gente passa. (Estudante 4)

Para mim, esse estágio integral é realmente a forma correta de formar um fisioterapeuta generalista... Há 2 anos eu estava em num congresso sobre fisioterapia oncológica e o palestrante perguntou quantas pessoas tinham pago na graduação essa disciplina. Eu, duas colegas aqui da instituição e mais três pessoas levantamos a mão. Então isso é um diferencial pro nosso currículo. (Estudante 3)

Além da percepção do entendimento técnico das diferentes áreas da fisioterapia, as estudantes reconhecem que o estágio integrado fornece subsídios para o desenvolvimento de habilidades e atitudes. Valores éticos e relação interprofissional são disciplinas que devem ser trabalhadas na prática e atreladas ao perfil do egresso fisioterapeuta.

O estágio foi fundamental pra gente ganhar habilidade, pra gente ganhar essa questão de comportamento entre um profissional e outro; como é que a gente vai chegar e falar futuramente com um profissional sobre determinado assunto. Não é só a questão da prática e da habilidade profissional, mas essa questão mesmo de ética, interação e comunicação entre profissionais. (Estudante 1) 


\section{CONCLUSÃO}

Nunes et al

A gente aprende a ter essa autonomia e quando começar [o tratamento], quando dar alta, e [aprende] a conversar com outros profissionais pra que eles entendam a nossa importância e pra que a gente não precise ser submisso. (Estudante 5)

[...] é a questão de quem você vai ser quando for profissional. Se você vai aceitar aquilo ou se você vai fazer a mudança ao seu redor. (Estudante 7)

A aproximação da prática profissional proporciona ao estudante a aprendizagem de forma significativa, a construção de conhecimentos, habilidades e atitudes com autonomia e responsabilidade. A junção dos domínios cognitivo, psicomotor e afetivo propicia a aquisição de visão ampla do campo de atuação ${ }^{28,30}$.

Além disso, Paranhos e Mendes ${ }^{26}$ ainda enfatizam que a proposta pedagógica que orienta o currículo integrado busca articular a atuação docente com a proposta de ensino, prática e teoria, IES e comunidade, passando a valorizar os pressupostos essenciais para a formação profissional com ênfase no SUS, em que se aplicam conhecimentos interdisciplinares.

No modelo de estágio integrado, os estudantes enfrentam desafios e situações que propiciam as necessidades reais de saúde da população, seja de forma individual ou coletiva. É necessário que se compreendam os porquês das ações. Por meio dessas experiências de aprendizagem, o estudante vai integrando seu conhecimento teórico à prática em um processo de construção didaticamente estruturado. Ele constrói seu raciocínio crítico e reflexivo durante a imersão nos diferentes ambientes de prática, relacionando conhecimento teórico com práxis, construindo e ampliando os domínios cognitivo, habilidade e, sobretudo, atitude.
No presente estudo, pudemos observar que os estudantes do curso de fisioterapia da IES onde foi realizada a pesquisa têm conhecimento acerca da integralidade na saúde, não apenas no seu conceito básico e de forma compartimentalizada, mas também incorporando o seu amplo sentido no cuidado aos pacientes. Os resultados obtidos divergem de alguns estudos realizados em outras localidades, possivelmente pela organização curricular diferente.

Outrossim, por se tratar de uma pesquisa de natureza qualitativa, com um número reduzido de participantes e apenas com o curso de fisioterapia, ela não permite uma generalização dos dados, sendo essa uma limitação observada no estudo.

Devido ao crescente número de instituições que ofertam o curso de fisioterapia no estado de Pernambuco, sugerem-se mais estudos com as outras IES da cidade e do estado, além de estender a pesquisa para conhecer também a vivência de docentes e preceptores.

\section{REFERÊNCIAS}

1. Silva MVS, Miranda GBN, Andrade MA. Sentidos Atribuídos à Integralidade: entre o que é preconizado e vivido na equipe muldisciplinar. Interface. 2017;21(62):589-99.

2. Lins KGV, Barbosa LNF, Carréra M, Menezes T, Santos ZC. Percepção de Residentes e Preceptores Sobre Integralidade da Atenção à Saúde em Programa de Residência Multiprofissional. Rev Diálogos. 2017;17:61-88.

3. Mendes JMR, Lewgoy AMB, Silveira EC. Saúde e interdisciplinaridade: mundo vasto mundo. Rev Ciência \& Saúde. 2008; 1(1): 24-32.

4. Araújo D, Miranda MCG, Brasil SL. 
Formação de Profissionais de Saúde na Perspectiva da Integralidade. Rev Baian de Saú Públ. 2007;31(1):20-31.

5. Brasil. Lei ${ }^{\circ} 8.080$, de 19 de setembro de 1990. Dispõe sobre as condições para a promoção, proteção e recuperação da saúde, a organização e o funcionamento dos serviços correspondentes e dá outras providências [internet]. Diário Oficial da União. 20 set 1990 [citado 2019 mar 03]. Disponível em: http://www.planalto.gov. br/ccivil_03/leis/L8080.htm.

6. Brasil. Ministério da Saúde. Secretaria de Atenção à Saúde. Núcleo Técnico da Política Nacional de Humanização. HumanizaSUS: Documento base para gestores e trabalhadores do SUS. 4. ed. Brasília: Editora do Ministério da Saúde; 2008.

7. Bispo Júnior JP. Formação em fisioterapia no Brasil: reflexão sobre a expansão do ensino e os modelos de formação. Hist Ciên Saúde. 2009;16(3):655-668.

8. Oliveira IC, Cutolo RLA. Humanização como expressão de Integralidade. $\mathrm{O}$ Mundo da Saúde. 2012;36(3):502-506.

9. Silva ID, Silveira MFA. A humanização e a formação do profissional em fisioterapia. Ciên Saúde Colet. 2011;16(Supl. 1):1535-1546.

10. Araújo D, Miranda MCG, Brasil SL. Formação de Profissionais de Saúde na Perspectiva da Integralidade. Rev Baian de Saú Públ. 2007;31(1):20-31.

11. Brasil. Conselho Nacional de Educação, Câmara de Educação Superior. Resolução CNE/CES 4, de 19 de fevereiro de 2002. Institui Diretrizes Curriculares Nacionais do Curso de Graduação em Fisioterapia [Internet]. Diário Oficial da União. 4 mar 2002 [citado 2017 abr 10]. Disponível em: http://portal.mec.gov.br/ cne/arquivos/pdf/CES042002.pdf

12. Machado D, Carvalho M, Machado B, Pacheco F. A Formação Ética do Fisioterapeuta. Fisioter em Mov. 2007;20(3):101-105.

13. Silva DJ, Da Ros MA. Inserção de profissionais de fisioterapia na equipe de saúde da família e Sistema Único de
Saúde: desafios na formação. Ciên Saúde Colet. 2007;12(6):1673-1381.

14. McMahon S, O’Donoghue G, Doody C, O’Neill G, Barrett T, Cusack T. Standing on the precipice: Evaluating Final-Year Physiotherapy Students' Perspectives of Their Curriculum as Preparation for Primary Health Care Practice. Phys Canada. 2016;68(2):188-196.

15. Korpi H, Peltokallio L, Piirainen A. Problem-Based Learning in Professional Studies from the Physiotherapy Students' Perspectives. The Intern Journ of PBL. 2019;13(1):1-19.

16. Gunn H, Hunter HD, Haas BM. Problem Based Learning in Physiotherapy education: A practice perspective. Physiotherapy. 2012;98(4):335-340.

17. Imafuku R, Kataoka R, Mayhara M, Suzuki H, Saiki T. Students' Experience in Interdisciplinary Problem-based Learning: A Discourage Analysis of Group Interaction. The Intern Journ of PBL. 2014;8(2)1-19.

18. Dolmans DHJM, De Grave W, Wolfhagen IHAP, Van der Vleuten CPM. Problem-based learning: future challenges for educational practice and research. Med Educat. 2005;39:732-741.

19. Almeida SM, Martins AM, Escalda PMF. Integralidade e formação para o Sistema Único de Saúde da perspectiva de graduandos em Fisioterapia. Fisioter Pesq. 2014;21(3):271-278.

20. Bardin, L. Análise de Conteúdo. 1. ed. São Paulo: Edições 70; 2016.

21. Minayo, MCS. O Desafio do Conhecimento - Pesquisa Qualitativa em Saúde. 14. ed. São Paulo: Hucitec Editora; 2014.

22. Fortes PAC. Ética, direitos dos usuários e políticas de humanização da atenção à saúde. Saúde Soc. 2004;13(3):30-35.

23. Signorelli MC, Israel VL, Corrêa CL, Motter AA, Takeda SYA, Gomes ARS. Um projeto político-pedagógico de graduação em Fisioterapia pautado em três eixos curriculares. Fisioter Mov. 
2010;23(2):331-340.

24. Aguilar-da-Silva RH, Rocha Júnior AM. Avaliação da problematização como método ativo de ensino-aprendizagem nos cenários de prática do curso de fisioterapia. Rev E-Curriculum. 2010;5(2):1-20.

25. Brasil. Ministério da Saúde. Secretaria de Gestão do Trabalho e de Educação na Saúde. Departamento de Gestão da Educação na Saúde. Política Nacional de Educação Permanente em Saúde: o que se tem produzido para o seu fortalecimento? 1. ed. rev. Brasília: Ministério da Saúde; 2018.

26. Paranhos VD, Mendes MMR. Currículo por competência e metodologia ativa: percepção de estudantes de enfermagem. Rev. Latino-Am. Enfermagem. 2010;18(1):1-7.

27. Lorenz RH. Papel do Preceptor na Residência Multiprofissional. Porto Alegre (RS): Universidade Federal do Rio Grande do Sul; 2010.

28. Castaneda L, Bergmann A, Bahia L. A Classificação Internacional de Funcionalidade, Incapacidade e Saúde: uma revisão sistemática de estudos observacionais. Rev. Bras Epidemiol. 2014;437-451.

29. Matos IB, Santos RS, Souza MC, Souza MP, Maciel RRBT. A Influência do Estágio Extracurricular na Construção do Conhecimento do Acadêmico de Fisioterapia. Cad Edu Saúde e Fis. 2017;4(8):23-30.

Recebido: 22/12/2019

Aprovado: 28/08/2020

30. Ceccim RB, Feuerwer LCM. Mudança na graduação das profissões de saúde sob o eixo da integralidade. Cad Saúde Pública. 2004;20(5):1400-1410. 